\title{
Estimation of urban sensible heat flux using a dense wireless network of observations
}

\author{
Daniel F. Nadeau • W. Brutsaert • M. B. Parlange • \\ E. Bou-Zeid • G. Barrenetxea - O. Couach • \\ M.-O. Boldi · J. S. Selker • M. Vetterli
}

Received: 18 December 2008 / Accepted: 26 August 2009 / Published online: 10 September 2009

(C) The Author(s) 2009. This article is published with open access at Springerlink.com

\begin{abstract}
The determination of the sensible heat flux over urban terrain is challenging due to irregular surface geometry and surface types. To address this, in 2006-07, a major field campaign (LUCE) took place at the École Polytechnique Fédérale de Lausanne campus, a moderately occupied urban site. A distributed network of 92 wireless weather stations was combined with routine atmospheric profiling, offering high temporal and spatial resolution meteorological measurements. The objective of this study is to estimate the sensible heat flux over the built environment under convective conditions. Calculations were based on Monin-Obukhov similarity for temperature in the surface layer. The results illustrate a good agreement between the sensible heat flux inferred from the thermal roughness length approach and independent calibrated measurements from a scintillometer located inside the urban canopy. It also shows that using only one well-selected station can provide a good estimate of the sensible heat flux over the campus for convective conditions. Overall, this
\end{abstract}

D. F. Nadeau $(\bowtie) \cdot$ M. B. Parlange · O. Couach · M.-O. Boldi · J. S. Selker

School of Architecture, Civil and Environmental Engineering, École Polytechnique Fédérale de Lausanne,

Station 2, 1015 Lausanne, Switzerland

e-mail: daniel.nadeau@epfl.ch

W. Brutsaert

School of Civil and Environmental Engineering, Cornell University, Hollister Hall, Ithaca, NY 14853-3501, USA

E. Bou-Zeid

Department of Civil and Environmental Engineering, Princeton University, Princeton, NJ 08544, USA

G. Barrenetxea $\cdot$ M. Vetterli

School of Computer and Communication Sciences, École Polytechnique Fédérale de Lausanne,

Station 14, 1015 Lausanne, Switzerland

G. Barrenetxea

Swiss Federal Institute for Forest, Snow and Landscape Research (WSL), Flüelastrasse 11,

7260 Davos Dorf, Switzerland 
study illustrates how an extensive network of meteorological measurements can be a useful tool to estimate the sensible heat flux in complex urban environments.

Keywords Sensible heat flux · Urban environment · Network of weather stations · Profile technique $\cdot$ Thermal roughness length $\cdot$ Monin-Obukhov similarity

\author{
Abbreviations \\ DEM Digital elevation model \\ EPFL École Polytechnique Fédérale de Lausanne \\ LUCE Lausanne Urban Canopy Experiment \\ MOS Monin-Obukhov similarity \\ RASS Radio acoustic sounding system \\ SODAR Sound detection and ranging
}

\title{
1 Introduction
}

Previous studies have shown that the sensible heat flux at the ground surface is often a key factor for the accurate modelling of air pollution over urban areas [1,13,16,21]. A larger sensible heat flux leads to thermally-induced turbulence and thus to increased vertical mixing rates of pollutants in the atmosphere.

In a city, due to the thermal properties of urban surfaces like concrete or asphalt, the surface energy budget is typically characterized by a high Bowen ratio: high sensible heat flux from the surface and low evaporation due to the absence of vegetation and an enhanced runoff. These properties of the surface have important impacts on the atmospheric dynamics. Good examples are the urban heat island effect, which has been subject to continuous investigations for more than 40 years now [24,35], and the local turbulent circulations at the street canyon level due to heated and shaded surfaces (building walls) and the surface topology $[29,48]$. Several urban schemes have been developed to model these city-induced phenomena (e.g. [32]).

The spatial variability of urban terrain complicates the estimation of the sensible heat flux. The existence of various surface types and different exposures to solar radiation in a complex surface geometry can lead to significant variations in heat fluxes over short distances. This problem is well-known, but for practical purposes various simplifications that assume homogeneous properties at the surface like Monin-Obukhov similarity (MOS) are still widely used to estimate the sensible heat flux in mesoscale models, typically with the scalar roughness approach $[15,49]$. When this method is used, one of the main difficulties is to define a representative value for the surface temperature. Several studies have addressed this problem. Voogt and Oke [51] for instance have considered the influence of what they call the total active surface area, allowing also contribution by lateral walls to the overall surface temperature.

One traditional technique to estimate the surface temperature is based on remote sensing measurements, from satellite or aircraft platforms. The spatial resolution offered by common tools like MODIS ( $\sim 1 \mathrm{~km}[26])$ is insufficient to account for the variability present at the surface. The latest improvements in the field of airborne hyperspectral imagery have shown nonetheless that surface temperature could be estimated with a spatial resolution as small as $6 \mathrm{~m}$ [53]. However, these thermal infrared remote sensing measurements are typically provide very low temporal resolution (one to a few measurements per day) and are only feasible 
under clear-sky conditions. In many cities, especially when aerosol particles are present in the atmosphere, this is a serious limitation even under a cloudless sky. In situ measurements do not suffer from this limitation, as they offer the possibility to continuously probe surface characteristics such as surface and air temperature, even under a thick cloud layer. The drawback of in situ measurements however is that a dense network of observations is needed to account for the spatial variability and this is technically not always possible.

In this study, on the basis of a dense network of wireless observations [2,25], it will be shown that it is possible to obtain a reliable estimate of the sensible heat flux in complex urban terrain. This will be accomplished with the following steps. First, the surface roughness characteristics will be identified based on near-neutral profile analysis. This will be followed by the determination of the thermal roughness length on the basis of a careful analysis of convective cases. The resulting estimation of sensible heat flux will then be tested against concurrently obtained scintillometer measurements inside the urban canopy. Finally, it will be shown that a good estimate of sensible heat flux can be obtained using only one station, located where a representative surface temperature is measured for practical long term applications.

\section{Background}

MOS remains the most commonly used tool to study land-atmosphere interactions within the atmospheric surface layer. Although MOS was originally derived for flat and homogeneous terrain $[8,34]$, several past studies have used it over heterogeneous terrain $[5,6,22]$ and even over cities [39]. Brutsaert [9] has shown however that when the vertical spatial scales are one or two orders of magnitude smaller than horizontal spatial scales, turbulence would tend to reduce the effect of these heterogeneities on the overall flow characteristics.

In urban micrometeorology studies, the so-called constant flux layer (also called the inertial sublayer) is generally taken to start at a height of two or three times the mean obstacle height [40], and to extend to the top of the atmospheric surface layer. The reasoning is that in this part of the surface layer, the turbulence is fully developed and the effect of surface features is blended. Below the inertial sublayer lies the roughness sublayer, in which MOS is not expected to hold as a result of the spatial variability of the turbulent fluxes of momentum and heat.

It should be mentioned however that the need to be two or three times above the mean building height to measure in the constant flux layer may be overly restrictive as the atmosphere over built environment seems to adjust more quickly based on recent Large-Eddy Simulations shown in Bou-Zeid et al. [7].

According to MOS, in the upper part of the surface layer above rough surfaces, the following equation for wind speed is expected to hold:

$$
\bar{u}=\frac{u_{*}}{k}\left[\ln \left(\frac{z-d_{0}}{z_{0}}\right)-\Psi_{m}\left(\frac{z-d_{0}}{L}\right)\right]
$$

where $\bar{u}$ is the time-averaged wind speed, $u_{*}$ the friction velocity, $k(=0.4)$ the von Kármán constant, $z$ the measurement height, $d_{0}$ the zero-plane displacement height, $z_{0}$ the momentum roughness length and $\Psi_{m}$ a stability correction term for momentum. Finally, $L$ is the Obukhov length, defined as

$$
L=\frac{-\rho u_{*}^{3}}{k g\left(\frac{H}{T_{a} c_{p}}+0.61 E\right)}
$$


where $\rho$ is the air density, $g$ the gravitational acceleration, $H$ the sensible heat flux, $T_{a}$ the air temperature, $c_{p}$ the specific heat of air at constant pressure and $E$ the rate of surface evaporation. In this study, the surface evaporation term in (2) is neglected. Similar to (1), for temperature, one can write

$$
\theta_{s}-\bar{\theta}=\frac{H}{k u_{*} \rho c_{p}}\left[\ln \left(\frac{z-d_{0}}{z_{0 h}}\right)-\Psi_{h}\left(\frac{z-d_{0}}{L}\right)\right]
$$

where $\theta_{s}$ is the surface temperature, $\bar{\theta}$ the time-averaged air potential temperature, $\Psi_{h}$ a stability correction term for heat and $z_{0 h}$ the thermal roughness length. This particular parameter $z_{0 h}$ is the surface intercept of the atmospheric surface layer potential temperature profile (e.g. $[10,12])$. Here it is assumed that the zero-plane displacement height for heat transfer is the same as that for the momentum transfer following the reasoning of Brutsaert [8].

In atmospheric models, simple relationships between the different roughness lengths are often assumed $\left(z_{0 h}=0.1 \mathrm{z}_{0}\right.$ for instance) [8]. Whereas this might be a good approximation over a vegetated surface [22], for built environments it is often a poor estimation. In some applications however $[14,49]$, the thermal roughness length is defined by the equation from Brutsaert [8] for bluff-rough surfaces:

$$
z_{0 h, B 82}=z_{0}\left[7.4 \exp \left(-2.46 R e_{*}^{0.25}\right)\right]
$$

where $R e_{*}=u_{*} z_{0} / v$ is the friction Reynolds number and $v$ is the kinematic viscosity for air. See also recent application by Kanda et al. [28].

\section{Methods}

\subsection{Study area}

The data used in this study were collected throughout the months of October 2006 to April 2007 over the École Polytechnique Fédérale de Lausanne (EPFL) university campus (see Fig. 1), located $5 \mathrm{~km}$ west of the city of Lausanne, Switzerland. The campus is a $750 \times 500 \mathrm{~m}$ site essentially consisting of buildings, roads, parking lots and vegetation including mature trees, bushes and grass. The plan area coverage of built-up structures is approximately $75 \%$ over the campus. The buildings have a typical height of $12-15 \mathrm{~m}$, the largest ones measuring up to $25 \mathrm{~m}$. The campus topography is relatively flat and is bordered by a $30 \mathrm{~m}$ mildly sloping ridge at a distance of some $700 \mathrm{~m}$ to the west.

The experimental site is in a region with a temperate climate. The regional mean air temperature for the period October to April is $6^{\circ} \mathrm{C}$ and the mean precipitation for this period is about $600 \mathrm{~mm}$. During the field campaign, the air temperature varied between -5 and $25^{\circ} \mathrm{C}$, with a mean air temperature of $7^{\circ} \mathrm{C}$ and the total precipitation was approximately $500 \mathrm{~mm}$. The measurement period was thus slightly warmer and drier than what is usually observed for that period of the year.

During the campaign, the predominant winds were from the north, where the fetch is a mixture of industrial land-use and residential areas (see Fig. 1a). This wind direction is typically associated with a synoptically-induced circulation called the bise, which is most frequent in spring [52]. Most of the bise episodes are associated with anticyclonic conditions (thus clear skies) and cold air advection. 

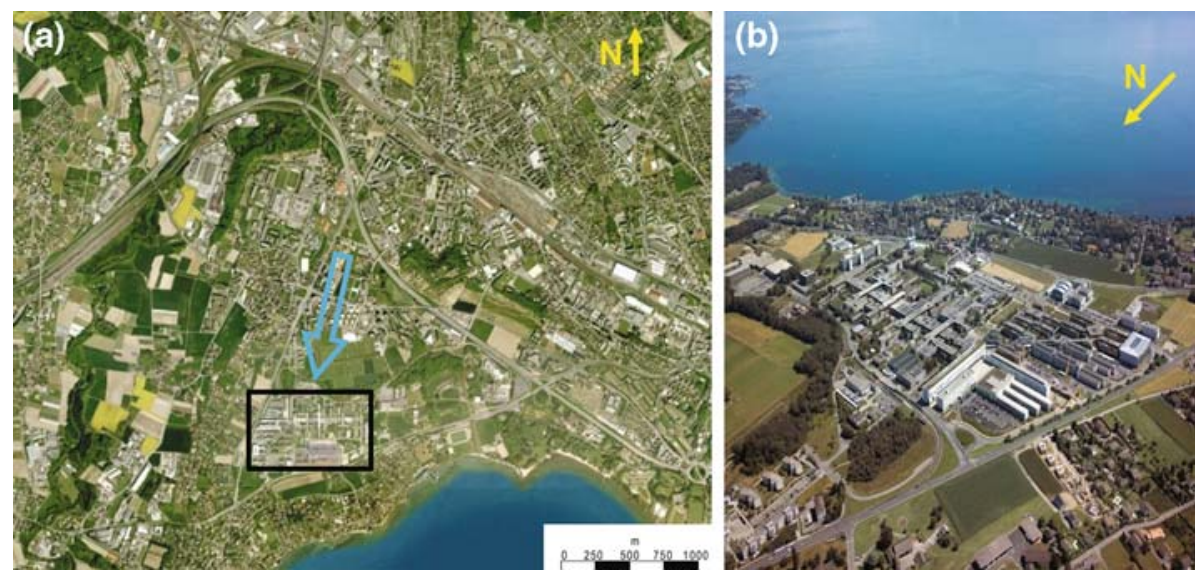

Fig. 1 a Satellite image of the EPFL campus (in black) and the surrounding region, which is a mix of built-up areas and small crop fields. The prevailing wind direction (blue arrow) is from the predominantly built region. b The EPFL campus. Photo by Alain Herzog

\subsection{Data collection}

The measurements were part of the Lausanne Urban Canopy Experiment (LUCE) which aimed to study the impacts of the spatial heterogeneities on the heat transfer in complex urban terrain.

Three types of observations were performed: (i) ground-based measurements of surface radiometric temperature; (ii) remote-sensing wind and temperature profiling; (iii) inside-canopy sensible heat flux measurements.

(i) A network of 92 wireless weather stations was deployed in the central part of the campus (see Fig. 2a), covering an area of $300 \times 400 \mathrm{~m}$. These low-cost stations, called Sensorscope stations $[2,25]$, are an innovative tool to study spatial variability in complex areas. The stations were deployed in a broad variety of locations over the campus: 57 were located at the ground level; 18 were located on terraces ( $\sim-12 \mathrm{~m}$ above ground) and 17 on rooftops ( $\sim 12-17 \mathrm{~m}$ above ground). They were also distributed over vegetation and impervious surfaces (e.g., concrete and asphalt). The stations were mounted with several meteorological sensors (e.g. air temperature, humidity, wind speed, etc.); however, in this particular study, only surface temperature measurements were used. The measurements were obtained using Zytemp TN901 infrared thermometers with a resolution of $0.6^{\circ} \mathrm{C}$ and a 30-s sampling rate. Each infrared thermometer measured a representative surface temperature over an area of approximately $1.5 \mathrm{~m}^{2}$.

(ii) Wind and temperature profiles were measured with a Scintec MFAS Doppler sound detection and ranging (SODAR) profiler and a radio acoustic sounding system (RASS), located at the southern end of the EPFL campus (see Fig. 2). Due to noise pollution constraints in an urban environment, the SODAR/RASS system operated with a reduced volume. The highest good-quality measurements reached a height of $400 \mathrm{~m}$, with a $10-\mathrm{m}$ vertical resolution. The lowest measurements were taken at a height varying between 30 and $40 \mathrm{~m}$. The resolution for the wind speed was $0.1 \mathrm{~m} / \mathrm{s}$ and for temperature, $0.2^{\circ} \mathrm{C}$.

(iii) A Scintec SLS-40 laser scintillometer was installed at the southern end of the campus. The transmitter and receiver were placed on tripods on the rooftops of two buildings, 

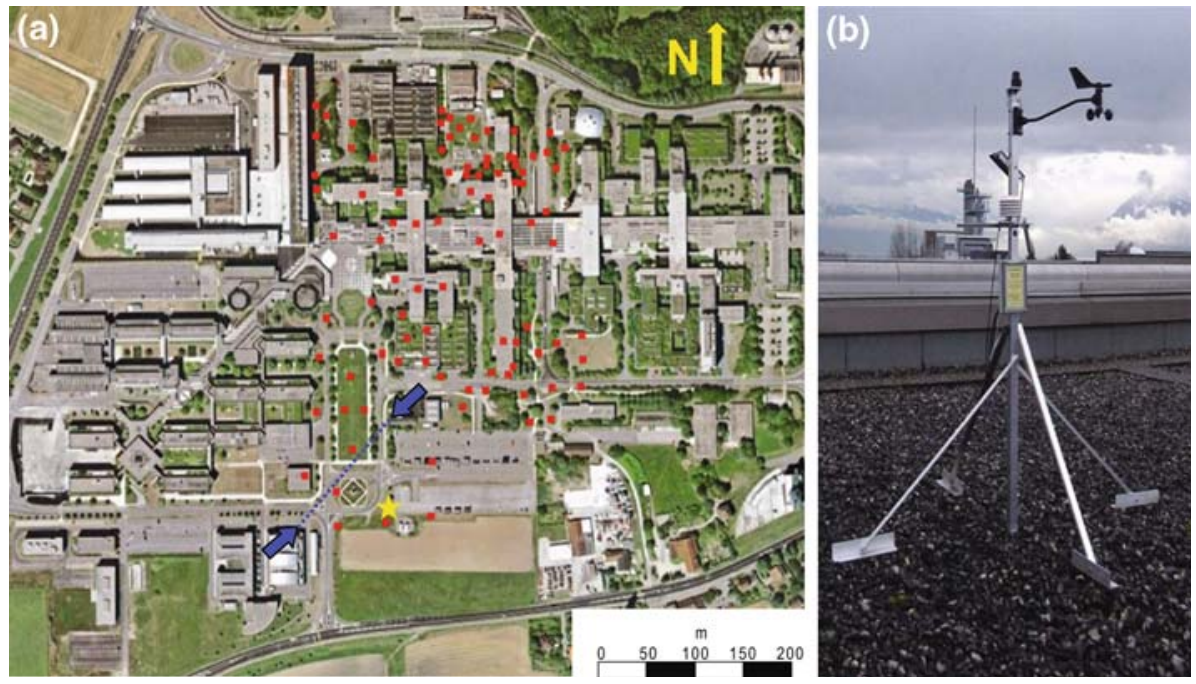

Fig. 2 a Distribution of meteorological instruments over the EPFL campus. The red squares denote the location of the Sensorscope stations; the yellow star the location of the SODAR/RASS system; the two blue arrows the location of the scintillometer's transmitter and receiver; the blue dotted line is the optical path of the scintillometer. b A Sensorscope station

$10 \mathrm{~m}$ high and $148 \mathrm{~m}$ apart. The scintillometer measured the averaged sensible heat flux over this $148 \mathrm{~m}$ path in a southwest-northeast orientation, as seen on Fig. 2a.

All the data used in this study were averaged over the same 30-min periods for the whole experiment duration. This holds for all Sensorscope stations (sampling rate $\sim 2 \mathrm{~min}$ ), as well as for the SODAR/RASS system (sampling rate $\sim 1 \mathrm{~min}$ ) and the scintillometer (sampling frequency $\sim 4 \mathrm{kHz}$ ).

\subsection{Range of validity for profile analysis}

The profile measurement height interval is based on two important considerations: (i) it must be at least two times above the mean building height $h$ to be above the roughness sublayer [40], and (ii) it must satisfy $z_{\max } / z_{\min }>2$ for accurate surface roughness evaluations [4]. The lowest continuous and reliable measurements provided by the SODAR/RASS are at $40 \mathrm{~m}$, which is more than three times the mean building height $(h \sim 12-15 \mathrm{~m})$. The highest profile measurement point used in the analyses was set at $100 \mathrm{~m}$ to fulfill criterion (ii). This maximum measurement height of $100 \mathrm{~m}$ represents a good trade-off that allows sufficient data points for the profile analysis, while remaining within the internal boundary layer of the campus.

\subsection{Determination of the source area}

Over complex and heterogeneous terrain, one needs to identify the upstream area contributing to the turbulence measurements at a height $z$ above the ground. Source area models provide a means to do so [43]. In this study, the source area model from Schmid [42] was used, which has been widely applied in previous land-atmosphere interactions studies [19,50]. While it 
assumes a uniform surface, this may be considered as a sufficient first approximation for the present analysis.

In Schmid's method, when the profile technique is used for flux estimations, one has to choose a height at which flux from the upwind source area will be evaluated. Horst [23] has shown that the footprint for profile-flux measurements has a similar upwind extent as the footprint for eddy-covariance measurements evaluated at the geometric mean of the lowest and highest profile measurement heights. In the present case, for measurements between 40 and $100 \mathrm{~m}$, the geometric mean is approximately equal to $60 \mathrm{~m}$.

Schmidt's method assumes that three parameters govern what the sensor is exposed to: the atmospheric stability, the turbulent diffusion and the wind direction [42]. Consider now an average case with weak unstable conditions $\left(\left(z-d_{0}\right) / L=-0.1\right)$ and high lateral turbulent diffusion $\left(\sigma_{v} / u_{*}=2\right.$, based on [50]). To account for variations of source areas due to wind direction, twelve 30-degree sectors were defined centered on the SODAR/RASS location. Each profile measured by the SODAR/RASS can thus be classified into a specific sector according to its main wind direction. However, given the prevailing wind directions and the distribution of sensors, only the two 30-degree sectors centered around $0^{\circ}$ and $30^{\circ}$ were considered.

Schmid's model also requires a prior knowledge of the surface roughness parameters. Based on the estimations of Grimmond and Oke [18] for a university campus, an a priori $d_{0}=10 \mathrm{~m}$ and $z_{0}=1 \mathrm{~m}$ were chosen. With these values of the parameters, the application of Schmid's method yielded the source areas shown in Fig. 3. These source areas correspond to locations where a majority of the Sensorscope stations were deployed.

Due to practical limitations, it is often impossible to install scintillometers at heights of two or three times the mean building height to measure in the so-called constant flux surface layer so as to have the same footprint area as the SODAR/RASS system. The limitations of sensible heat flux measurements through scintillometry inside the roughness sublayer were investigated by Kanda et al. [27] and Roth et al. [41]. In both studies, the authors recommend the use of an "urban form" of the MOS equation for such cases, but their derivations are

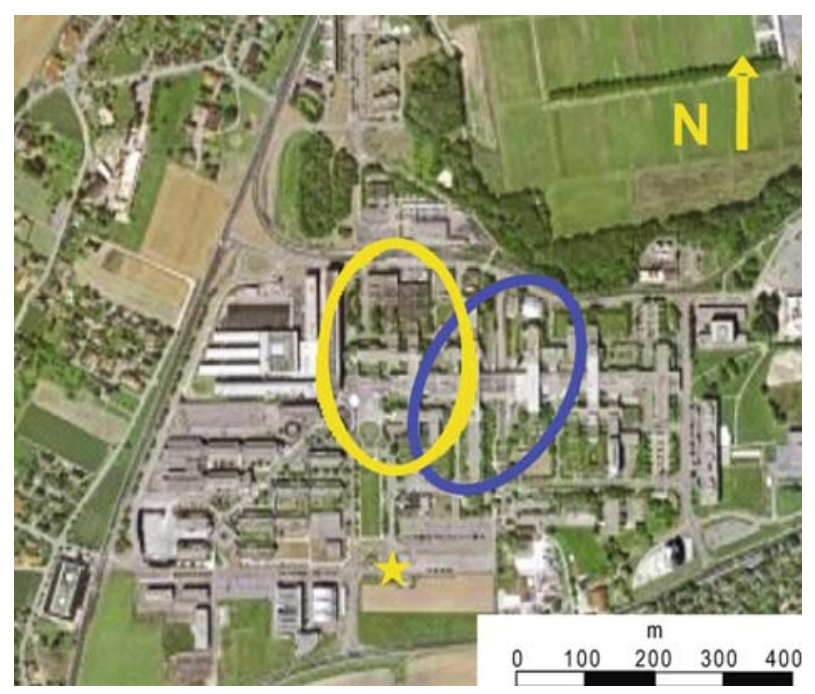

Fig. 3 Source areas for the $0^{\circ}$ wind sector (yellow) and for the $30^{\circ}$ wind sector (blue) obtained with Schmid's method [42]. The star indicates the location of the SODAR/RASS system 
site-specific and cannot be applied to the present study. As a result, we decided to use the scintillometer measurements without any correction. This will yield an adequate, although not highly precise, estimate of the surface fluxes over the footprint area of the scintillometer.

Nevertheless, one question that naturally arises is whether the scintillometer measurements, taken at a height of about $12 \mathrm{~m}$ inside the roughness sublayer, can be compared or analyzed in conjunction with SODAR/RASS data, given the different heights and footprints. A close examination of the footprint of the SODAR/RASS indicates that it is mainly a built-up area, with a small fraction of vegetated surfaces. In Fig. 2, bearing in mind the path-averaging of the scintillometer, one can note that the expected footprint area of the scintillometer will also consist of mainly built-up areas. Hence the two footprints, while not identical, have very similar land-use distributions and are expected to have comparable average fluxes.

In light of the above, we conclude that the scintillometer measurements provide a good estimate of the heat exchanges at the campus scale.

\section{Results and discussion}

\subsection{Determination of the zero-plane displacement height}

In an urban environment, the roughness elements are close to each other and the building roofs act as a displaced surface. To determine the zero-plane displacement height $d_{0}$ inside the source areas shown in Fig. 3, the mean height of the obstacles was calculated with the help of a high resolution Digital Elevation Model (DEM). A well accepted estimation of $d_{0}$ is

$$
d_{0}=\frac{2}{3} h
$$

where $h$ is the mean building height [8]. It was found that $d_{0}=8.2 \mathrm{~m}$ for the $0^{\circ}$ wind sector and $d_{0}=7.6 \mathrm{~m}$ for the $30^{\circ}$ wind sector.

\subsection{Determination of the momentum surface roughness}

For near-neutral stability conditions, the turbulence is mostly generated mechanically with thermal buoyancy effects small in comparison. As a result, the stability correction term in (1) may be taken as zero, yielding:

$$
\ln \left(z-d_{0}\right)=\frac{\bar{u}}{k u_{*}}+\ln \left(z_{0}\right)
$$

Thus, for known values of $z, d_{0}$ and $\bar{u}$ from SODAR profiles, a linear regression of the measured $\bar{u}(z)$ yields immediately $u_{*}$ and $z_{0}$ (see Fig. 4 ).

Due to its low sampling frequency, the SODAR/RASS cannot take the turbulence measurements needed to quantify stability by means of the Obukhov length (2). An alternative means to assess the stability of the atmosphere is the gradient Richardson number $R i_{g}$ defined as

$$
R i_{g}=\frac{\frac{g}{\bar{\theta}} \frac{\partial \bar{\theta}}{\partial z}}{\left[\frac{\partial \bar{u}}{\partial z}\right]^{2}}
$$



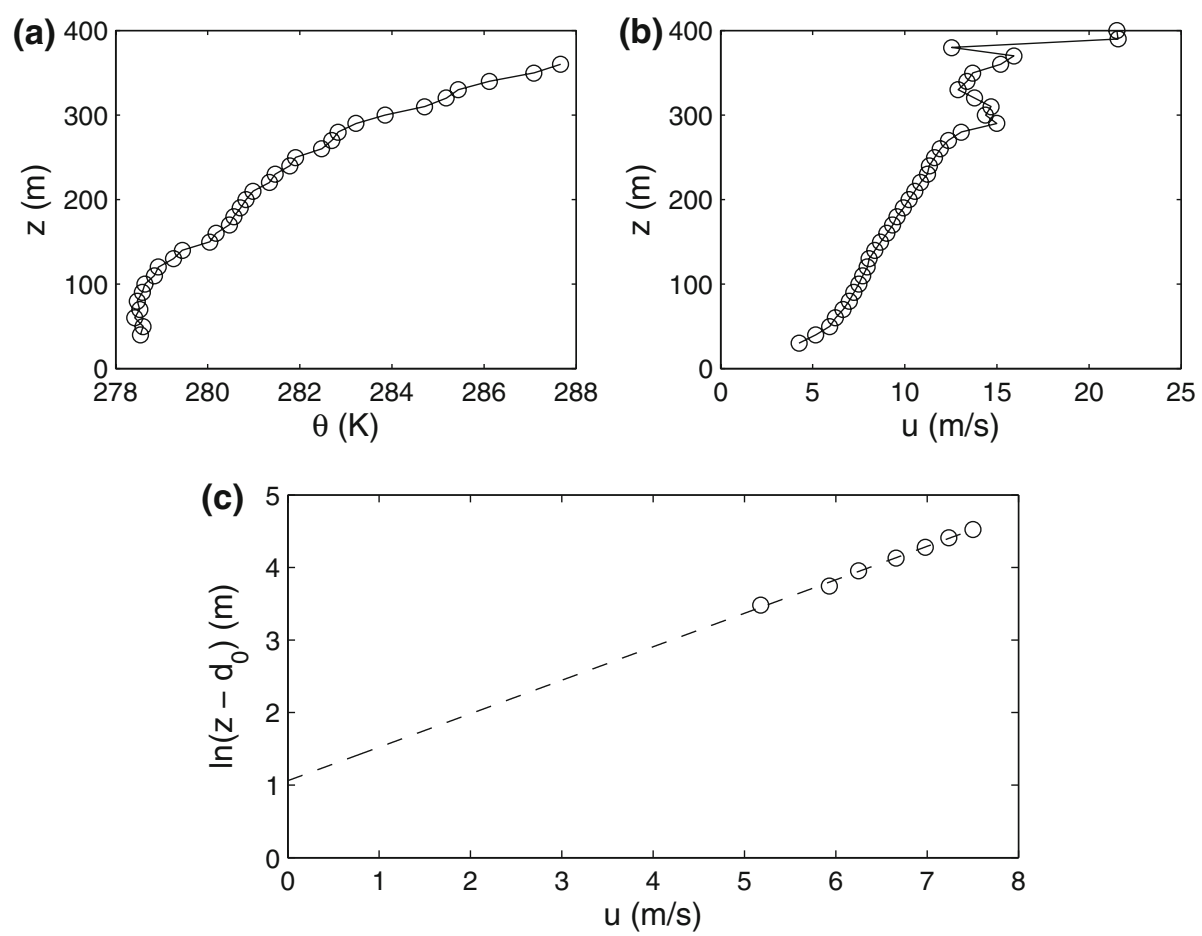

Fig. 4 Sample near-neutral profile used for the calculation of $z_{0}$, measured on 2 November 2006 at 02:30 (local time). Circles illustrate the measurement heights. a Potential temperature versus measurement height. b Wind speed versus measurement height. c The dashed line shows the regression curve for $40 \leq z \leq 100 \mathrm{~m}$ to obtain the friction velocity $u_{*}$ and the surface momentum roughness $z_{0}$

Near-neutral atmospheric profiles are typically found when strong winds (high mechanical shear) and cloudy conditions (low surface heating) are observed; however, those conditions tend to be infrequent $[37,46]$. In this study, no distinction is made between the so-called "truly neutral" and the "conventionally neutral" atmospheric layers as discussed by Zilitinkevich and Esau [54].

Thus, to identify near-neutral profiles, the following criteria are applied for $40 \mathrm{~m} \leq z \leq$ $100 \mathrm{~m}$ : (i) $\bar{u} \geq 5 \mathrm{~m} / \mathrm{s}$; (ii) least-square fitting of $\ln \left(z-d_{0}\right)$ versus $\bar{u}$ gives a correlation coefficient $r \geq 0.5$; (iii) $\left|R i_{g}\right| \leq 0.1$; (iv) weak directional wind shear with height. The criteria used for the selection of SODAR/RASS profiles are based on the following considerations. Criterion (i) is used as a trade-off between high wind speeds and sufficient number of profiles suitable for the analysis. Indeed, approximately $5 \%$ of the profiles recorded by the SODAR/RASS system have wind speeds greater than $5 \mathrm{~m} / \mathrm{s}$ for $40 \mathrm{~m} \leq z \leq 100 \mathrm{~m}$. Criterion (ii) is used to ensure that the wind speed profiles are in relative agreement with (6). Criterion (iii) is based on the reported range of $R i_{g}$ values for near-neutral conditions found in [3]. Finally, criterion (iv) is used to minimize departure from the source areas determined in Sect. 3.4 for each wind sector.

Out of 16,128 atmospheric profiles measured during the campaign, 108 could be classified as near-neutral. After a visual inspection to remove profiles with discontinuities, only 38 were retained to calculate the momentum surface roughness $z_{0}$. A sample profile in good agreement with the logarithmic profile under near-neutral conditions is shown in Fig. 4. 
The wind speed profiles were regressed for $50 \pm 10 \mathrm{~m} \leq z \leq 90 \pm 10 \mathrm{~m}$. Each of the 38 cases was inspected to locate the range of applicability of (6) to calculate $z_{0}$. The logarithmic mean value of the momentum surface roughness was calculated to be $z_{0}=2.1 \mathrm{~m}$ and $z_{0}=1.5 \mathrm{~m}$ for 0 and $30^{\circ}$ winds, respectively. Although these two values may appear relatively large compared to other values in the literature (e.g. [46]), they are well within the range of expected values for similar environments.

\subsection{Definition of the surface temperature}

An example of the impact of surface type on the radiometric surface temperature is shown for a clear sky day in Fig. 5. Note that although not shown in Fig. 5, the standard deviation values for $T_{s}$ follow a similar diurnal pattern, with $\sigma_{T_{s}} \approx 1.5^{\circ} \mathrm{C}$ at night time and $\sigma_{T_{S}} \approx 4.5^{\circ} \mathrm{C}$ in the early afternoon for all surface types.

Over vegetation, a large part of the incoming solar radiation is used for evaporative cooling, whereas over built-up surfaces, this energy is absorbed by asphalt or concrete. This can lead to temperature differences of several degrees (in this case of Fig. 5 up to $7^{\circ} \mathrm{C}$ ) in the early afternoon for clear sky days.

Since this time of the day typically corresponds to the largest daily sensible heat fluxes observed, it stresses the importance of defining the surface temperature as the combination of the surface temperature from each surface type. For the present study, this was done by linear weighting of the respective area-fractional coverage as follows

$$
\theta_{s}=f_{b}\left\langle T_{s, b}\right\rangle+f_{v}\left\langle T_{s, v}\right\rangle
$$

where $f_{b}$ and $f_{v}$ are the fractions of the surface covered with built structures and vegetation, respectively; $T_{s, b}$ and $T_{s, v}$ are the average of radiometric surface temperatures recorded over built structures and vegetation, respectively.

A land use analysis was performed for the two source areas using the plan surface areas. For the $0^{\circ}$ wind sector these were found to be $f_{b}=0.83$ and $f_{v}=0.17$ and for the $30^{\circ}$ wind sector, which has a greater vegetation cover, $f_{b}=0.65$ and $f_{v}=0.35$.

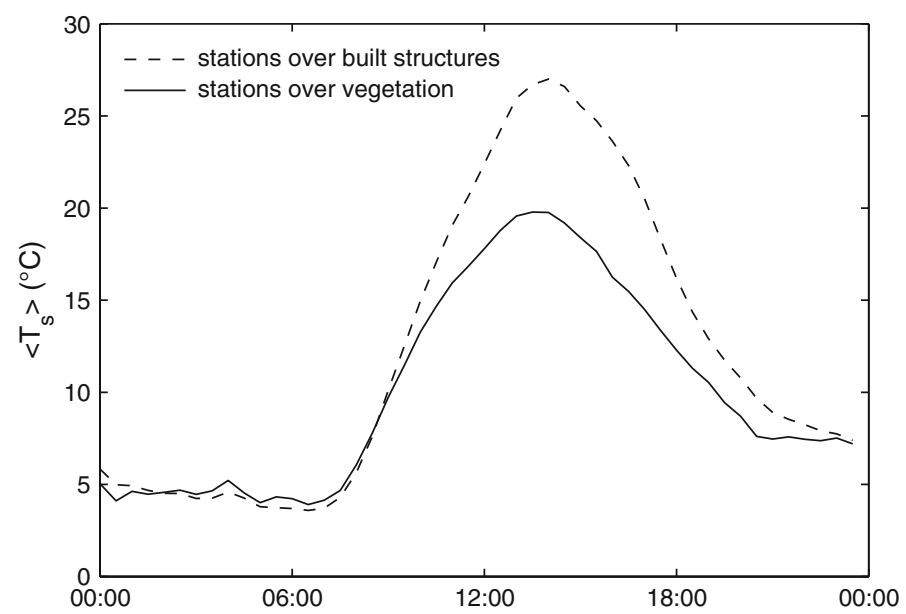

Fig. 5 Daily evolution of averaged surface temperature for the 30 stations over built structures (dotted curve) and for the 62 stations over vegetation (solid curve) for a clear sky day (14 March 2007) 
4.4 Determination of the thermal roughness length

A common way to report $z_{0 h}$ values is through the dimensionless number $k B^{-1}$, first introduced by Owen and Thomson [36] and defined here as

$$
k B^{-1}=\ln \left(\frac{z_{0}}{z_{0 h}}\right)
$$

For vegetative homogeneous surfaces, it is common to assume $k B^{-1} \approx 2$ [8]. Over heterogeneous surfaces, this ratio increases drastically. Malhi [31] reports $k B^{-1} \approx 6$ for free-standing vine bushes and $k B^{-1} \approx 23$ for woody bushes with isolated trees. Sugita and Brutsaert [47] found $k B^{-1} \approx 15$ under spring conditions for vegetated small hills and $k B^{-1} \approx 5$ for the same site under fall conditions. However, the authors also pointed out that $z_{0 h}$ depends strongly on the way in which the surface temperature is measured. Stewart et al. [45] found $k B^{-1}$ ranging from 3.5 to 12.5 for eight different semiarid rangeland sites. Kohsiek et al. [30], for a flat semi-arid area, found $k B^{-1}=3.68$. Voogt and Grimmond [50] found $k B^{-1}$ around 20-27 for a light industrial site in Vancouver, using the radiometric surface temperature.

Thus, to identify the most appropriate $z_{0 h}$, we look for cases with (i) consistent northerly winds with height; (ii) $R i_{g}<-0.1$; (iii) sufficient percentage of Sensorscope stations operating. To avoid anomalous outcomes due to temperature inversions between the ground and the lowest SODAR/RASS temperature measurement $\theta$, the heat flux is computed only for cases where $\theta_{s}>\theta$.

With a known $z_{0 h}$, and taking the values of $d_{0}$ and $z_{0}$ computed for the two different inflow wind directions, one can now solve for $u_{*}$ between the "reasonable" limits of 0 and $0.9 \mathrm{~m} / \mathrm{s}$ and $H$ positive up to $500 \mathrm{~W} / \mathrm{m}^{2}$ that minimize the following sums:

$$
\begin{array}{r}
\sum_{z=40 \mathrm{~m}}^{100 \mathrm{~m}}\left[\frac{u_{*}}{k}\left(\ln \left(\frac{z-d_{0}}{z_{0}}\right)-\Psi_{m}\left(\frac{z-d_{0}}{L}\right)\right)-\bar{u}\right]^{2} \\
\sum_{z=40 \mathrm{~m}}^{100 \mathrm{~m}}\left[\frac{H}{\rho k c_{p} u_{*}}\left(\ln \left(\frac{z-d_{0}}{z_{0 h}}\right)-\Psi_{h}\left(\frac{z-d_{0}}{L}\right)\right)-\theta_{s}+\bar{\theta}\right]^{2}
\end{array}
$$

Since $u_{*}$ and $H$ are not known at first, the Obukhov length is undefined. An initial guess for $u_{*}$ and $H$ (e.g. taking $z / L=0$ ), combined with a few iterations between (10) and (11) is thus necessary. If convergence is not met after a few iterations, the profile is considered not suitable for our analysis and is thus discarded.

Heat flux calculations were performed by setting the $k B^{-1}$ at constant values from 2 to 24 with increments of 1 . The lower end of this interval is a typical value of $k B^{-1}$ for vegetation [8] whereas the upper end of the interval was reported by Voogt and Grimmond [50] as being characteristic of light industrial areas. Figure 6 reports the comparison of the sensible heat fluxes obtained with this approach for different values of $k B^{-1}$ with the scintillometer-derived heat flux.

In the present case, for $k B^{-1}=2$, which is typically valid for vegetated areas, there is a poor correlation $(r=0.33)$ and an overestimation of the sensible heat flux when compared to scintillometer measurements. At the upper end of the range, for $k B^{-1}=24$, the correlation is almost double $(r=0.64)$, but the sensible heat flux obtained clearly underestimates the measurements by the scintillometer. The use of $k B^{-1}=6$ still yields a relatively good, albeit slightly lower, correlation with the scintillometer data $(r=0.61)$, but the mean slope through the origin is very close to $1(m=0.92)$. Good agreement between the surface fluxes 

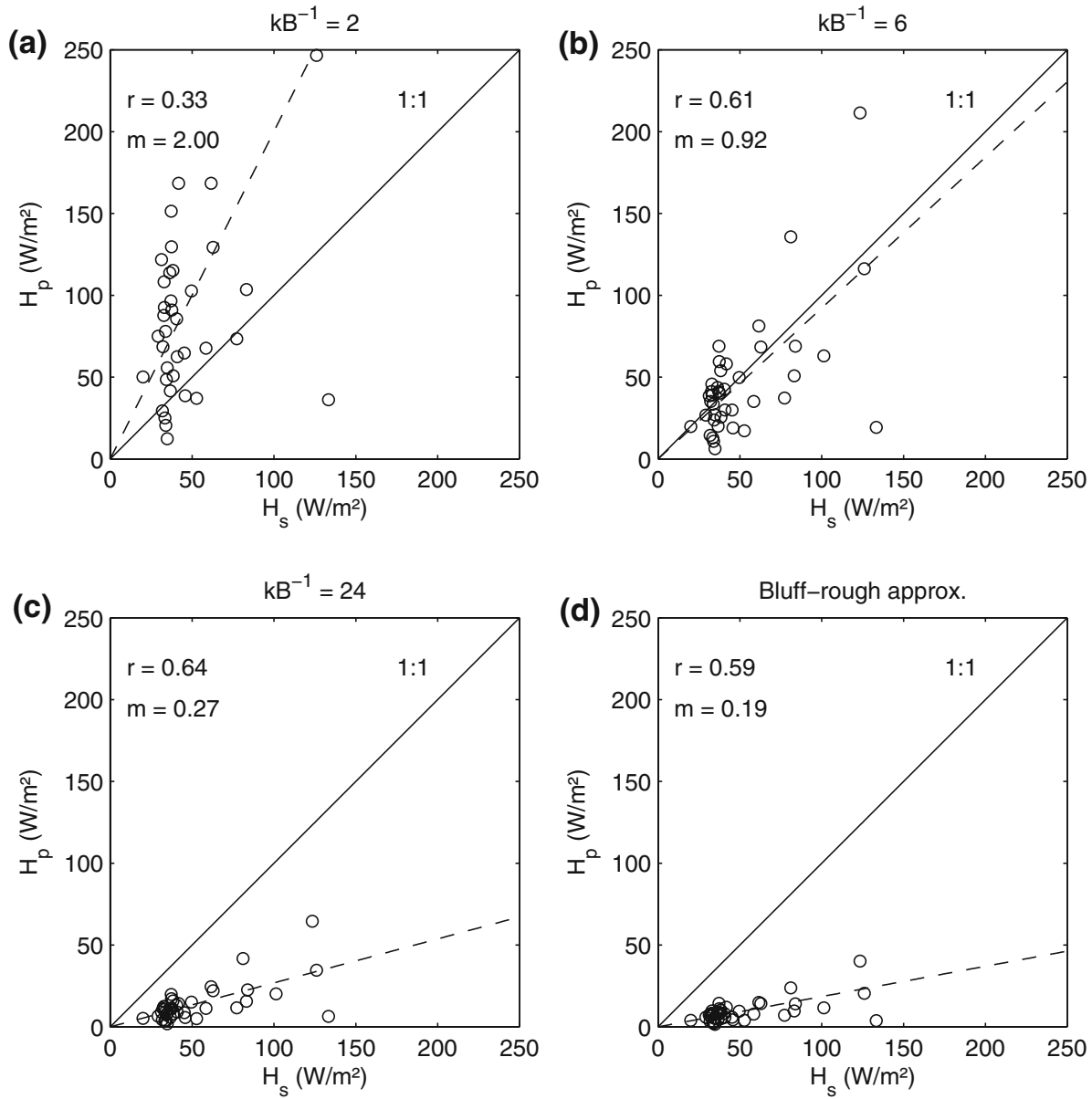

Fig. 6 Comparison between the sensible heat flux obtained by means of the profile technique $\left(H_{p}\right)$ with: $\mathbf{a} k B^{-1}=2 ; \mathbf{b} k B^{-1}=6 ; \mathbf{c} k B^{-1}=24 ; \mathbf{d}$ the bluff-rough surfaces approximation; against scintillometer measurements $\left(H_{S}\right)$. For each case, the correlation coefficient and the mean slope $m$ of the line through the origin through the origin $m$ (dashed) are also shown

of sensible heat obtained from profile measurements compared to high frequency turbulent measurements was also found in previous studies over heterogeneous terrain (e.g. [11]).

The present results show that the $k B^{-1}$ value found is intermediate between the values for vegetation and urban environments, although much smaller than the approximation for bluffrough surfaces. Recent studies have shown that this parameterization by Brutsaert (i.e. (4)), once implemented in mesoscale meteorological models, was capable of accurately reproducing urban surface temperature patterns observed by satellite imagery [14,49]. A possible explanation for this intermediate $k B^{-1}$ could be that the vegetation simply plays a more important role in the heat transfer over the EPFL campus and surrounding region than over a major city with presumably less vegetation.

Note that with $k B^{-1}=6$, the derived values of $u_{*}$ normalized by the wind speeds at $100 \mathrm{~m}$ are typically found between 0.08 and 0.15 . This is in good agreement with Parlange and Brutsaert [38] who found $u_{*} / U=0.131$ over a forested area for the same reference height. 
Overall, this demonstrates that the friction velocities obtained with the iterative procedure by means of (11) and (12) are reasonable.

Uncertainties in the zero-plane displacement height $d_{0}$ determined in Sect. 4.1 could lead to a different optimal $k B^{-1}$. Indeed, $d_{0}$ is defined on the mean building height $h$ inside the source area while the latter is dependent on the atmospheric conditions. A sensitivity analysis we undertook by varying stability and turbulent diffusion for the source area showed that the derived $d_{0}$ (which was about $8 \%$ lower than the value obtained with the original stability) results in the same optimal $k B^{-1}$ of 6 .

It should be emphasized once again that these comparisons were made with the assumption that the scintillometer was measuring a representative heat flux over the campus, given a mix of vegetation and surrounding buildings. In fact, the values obtained by the scintillometer which are used to calibrate $k B^{-1}$ are definitely typical of measurements over this type of surface in winter and early spring. Spronken-Smith [44], in a study of energy fluxes over a suburban area in New Zealand, reports ensemble means of sensible heat flux peaking at $50-60 \mathrm{~W} / \mathrm{m}^{2}$ between 12:00 and 14:00 for the middle of winter. Grimmond [17] reports slightly higher values over a suburb of Vancouver for measurements taken in January and February. Over the same area, for spring conditions, sensible heat fluxes values reach 125$150 \mathrm{~W} / \mathrm{m}^{2}$ in the early afternoon. All seem to agree well with the scintillometer measurements obtained in the present study. Additionally, these measurements are also of the same order of magnitude as other energy budget components measured within the same region (e.g. [20]).

Several reasons might explain the scatter in $H_{p}$ (from 10 to $70 \mathrm{~W} / \mathrm{m}^{2}$ ) observed on Fig. 6 with $k B^{-1}=6$ when the scintillometer reports values close to $40 \mathrm{~W} / \mathrm{m}^{2}$. It was noted that most of the $H_{S}$ values around $40 \mathrm{~W} / \mathrm{m}^{2}$ were measured during a common 3-day period at the end of December 2006 characterized by high winds and partly cloudy conditions. So not surprisingly, profile measurements of the atmospheric surface layer are challenging and the derivation of the surface heat flux is expected to be variable as shown in Fig. 6. Other possible sources of errors include the instrumental uncertainties and the neglect of the heat coming out of the building exhaust vanes.

\subsection{Spatial variability of the surface temperature: two examples}

In Sect.4.3, the impact of the different surface types found in urban areas on the surface temperature was illustrated. A reasoning based on area-fractional coverage of these surface types led to (8), a simplified model for the surface temperature.

In reality, strong microscale variations exist in the surface temperature distribution. The objective of the current section is to quantify these variations to illustrate the difficulty of accurately defining a representative surface temperature for the area of interest.

The spatial distribution of the surface temperature field can be illustrated by considering two extreme special cases, namely clear sky conditions (see Fig. 7) and overcast conditions (see Fig. 8).

The interpolated surface temperature fields over the campus shown in these figures were computed using the universal kriging framework as outlined in [33]. Note that the campus relief obtained from the DEM was used in the interpolation process of the surface temperatures.

Three factors appear to be causing spatial heterogeneities in the skin temperature field: solar radiation, surface type and elevation. For the case under sunny conditions (Fig. 7), the temperatures range between 10 and $36^{\circ} \mathrm{C}$ where for the cloudy conditions case (Fig. 8), they range between 8 and $11.5^{\circ} \mathrm{C}$. A closer look at Fig. 7 suggests a good correlation between 
(a)

(b) $\quad \times 10^{5}$

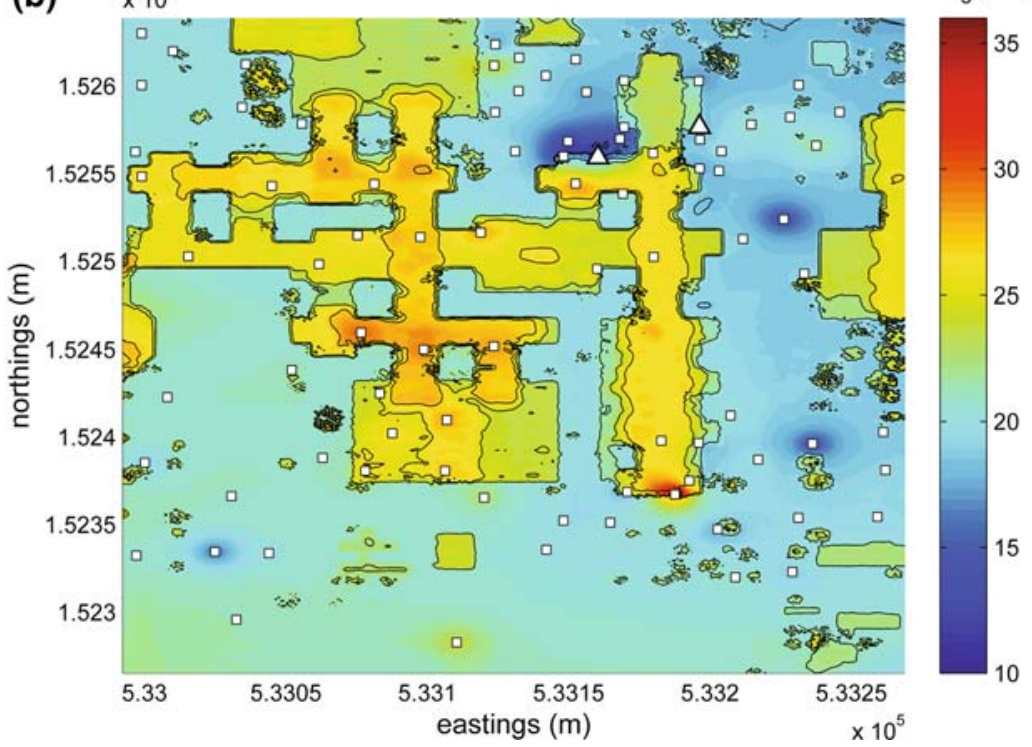

Fig. 7 a Sky conditions over the EPFL campus on 14 March 2007 at 13:30 local time. b Spatial interpolation of the radiometric surface temperature measured by the stations (illustrated as squares) at the same time. The index stations (see next section) are shown as triangles. The solid black contour lines are obtained from the campus DEM

exposure to solar radiation and surface temperature values. Indeed, Fig. 7 represents early afternoon conditions, thus stations close to south-facing walls reported the highest surface temperature values.

The influence of surface type can also be clearly observed, because stations over built structures reported higher temperatures than those at the ground, where most of the vegetation is found.

These two examples suggest an increasing radiometric surface temperature with height. This can be explained by the fact that higher surfaces are more strongly exposed to solar radiation (thus to an enhanced heating) as the shading caused by surrounding obstacles decreases with height. Some of the lower rooftops of the campus are partly vegetated areas in contrast with the higher rooftops which are all made of impervious surfaces. The difference in surface albedos also leads to an increasing surface temperature with height.

\subsection{Estimation of sensible heat flux using individual stations}

Up to this point, the heat fluxes were calculated by means of (3), in which $\theta_{s}$ was determined by means of (8) with measurements of $T_{s}$ at 92 wireless stations. To maintain such a large number of ground stations is rarely sustainable and usually only one or a few stations may be maintainable in the long term. Sensorscope technology is excellent for rapid fieldcampaign deployments for periods from a month up to a year, but currently not for 


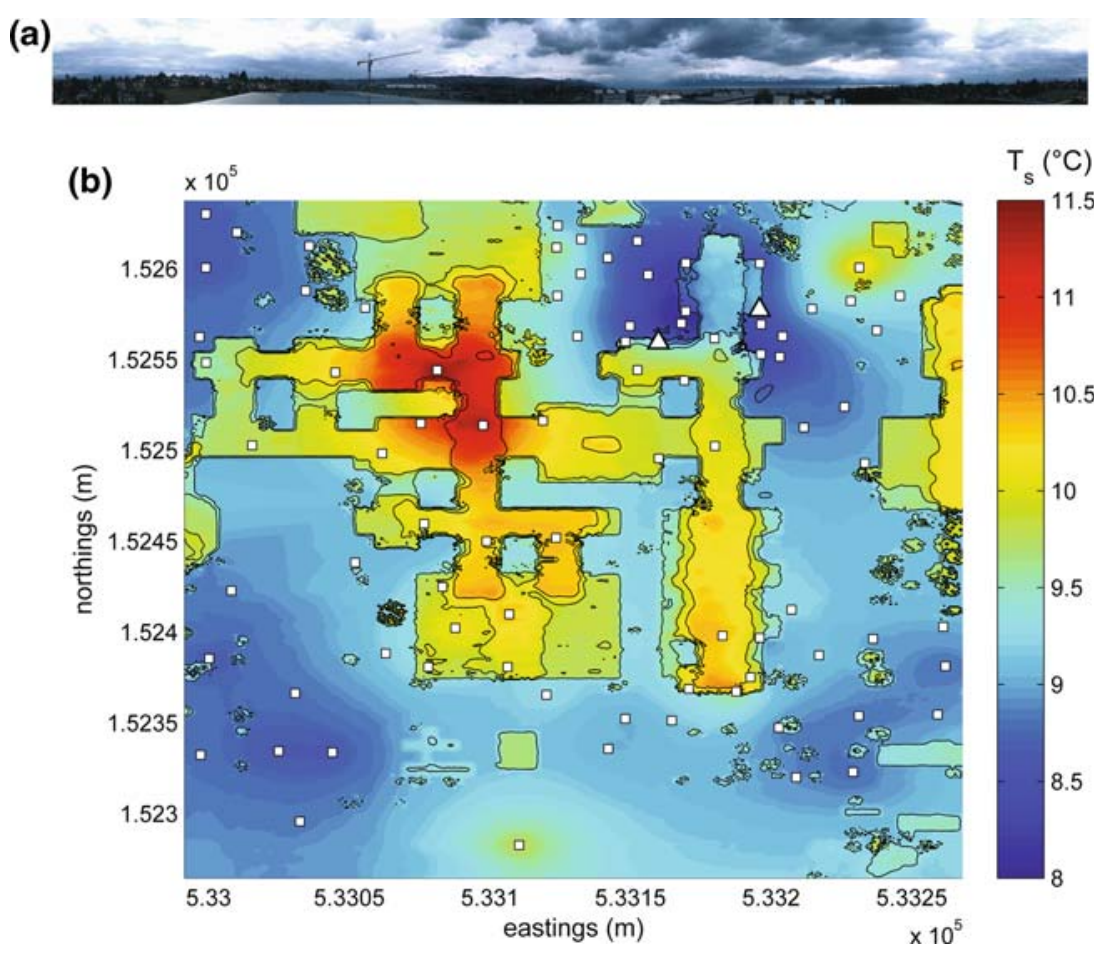

Fig. 8 a Sky conditions over the EPFL campus on 24 March 2007 at 15:30 local time. b Spatial interpolation of the radiometric surface temperature measured by the stations (illustrated as squares) at the same time. Note that the temperature range in this figure is smaller than the one used in Fig. 7. The index stations (see next section) are shown as triangles. The solid black contour lines are obtained from the campus DEM

permanent installation. It is therefore of interest to investigate the possibility of applying the present method with $T_{S}$ from only one station.

Thus, with $k B^{-1}=6$, for convective conditions and northerly winds, stations were ranked according to their correlation with the scintillometer measurement and to the value of the mean slope of the line through the origin. Two stations were found to provide a useful estimate of an appropriate surface temperature measurement for sensible heat flux determination over the urban area (see Fig. 9). Indeed, in the two cases, the mean slope of the line through the origin is close to one and the correlation coefficient greater than 0.8 .

Stations 14 and 15 were located 12 and $8 \mathrm{~m}$ above ground, respectively. Station 14 was located $3 \mathrm{~m}$ away from an adjacent 4-m tall north-facing wall whereas station 15 was $6 \mathrm{~m}$ away from an east-facing 4-m tall wall.

Interestingly, both stations were situated on the overlap of the two source areas studied and over a "green" (i.e. vegetated) rooftop (refer to Figs. 2, 3, 7, 8). Figure 5 already showed that stations over vegetation were reporting smaller $H_{p}$ values than stations over built-up structures for a sample sunny day.

On the other hand, it was also shown with Fig. 7 and 8 that the interpolated surface temperatures tend to be higher with increasing height. These findings suggest that, in the absence of a dense network of ground observations, the ideal locations for an "index" station, measuring a surface temperature representative of the source area, would be on an elevated vegetated surface inside the source area. 

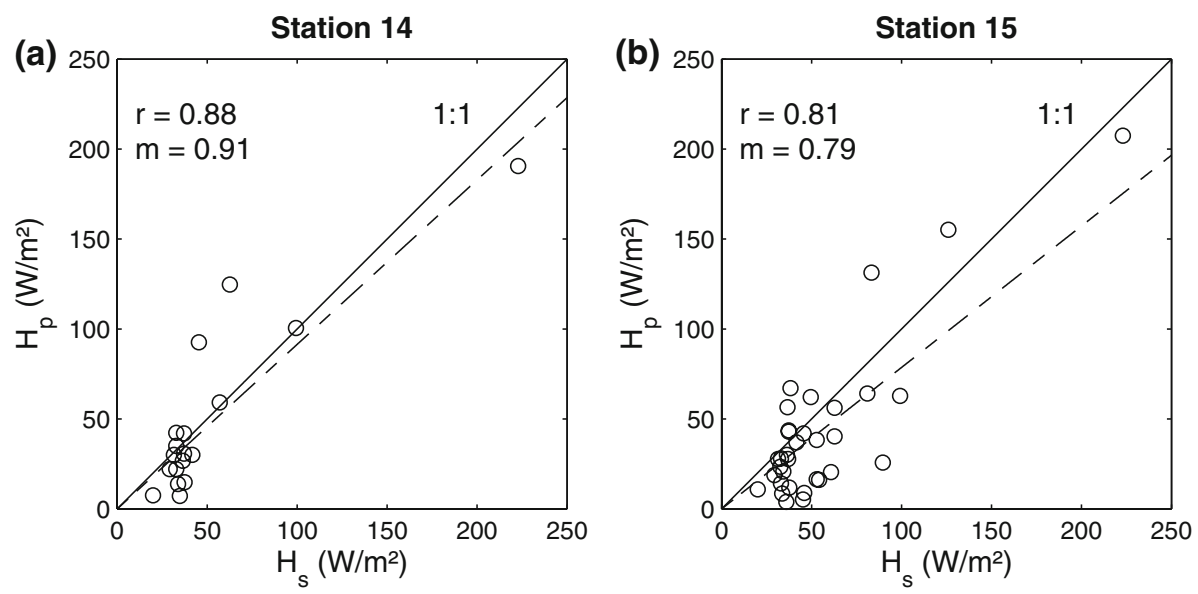

Fig. 9 Comparison between the sensible heat flux obtained by means of the profile technique $\left(H_{p}\right)$ with $k B^{-1}=6$ against scintillometer measurements $\left(H_{S}\right)$ using $\theta_{S}=T_{S}$ from two different stations: a 14 and b 15 . For each case, the correlation coefficient $r$ and the mean slope $m$ of the line through the origin (dashed) are also shown

As expected, not all stations led to a good agreement with the scintillometer measurements. The lowest correlation $(r=0.03)$ is found for station 55 , located over grass at the ground level and shielded to the east by a large building. The poor estimation of sensible heat flux provided by this station illustrates the importance of the accurate identification of the location of the index station.

\section{Conclusions}

This study presents a new method to estimate the sensible heat flux in an urban area by using a dense wireless network of ground observations in conjunction with profile measurements at a single location.

With $k B^{-1}=6$, relatively good agreement $(r=0.61, m=0.92)$ between this method and inside-canopy scintillometer measurements of sensible heat flux is obtained. High spatial resolution interpolation maps of surface temperature for clear and sunny conditions showed the considerable variability that can exist inside a complex urban area, thus emphasizing the difficulty of accurately defining a representative surface temperature for the area of interest. However, the present approach also showed that using only one well-selected station can provide a good estimate of the sensible heat flux over the campus for convective conditions.

It should be pointed out that the results of this study are based in part on the assumption that the scintillometer measurements used as a calibration dataset were representative of the heat fluxes between the urban surfaces and the atmosphere. Given the logistical constraints, the scintillometer was installed near the canopy top. Nevertheless, the facts that the scintillometer footprint had a similar land-use distribution as the profile footprint and that the scintillometer measurements were clearly typical of values over this type of surfaces and for that period of the year, justified the use of these measurements as a calibration dataset.

The method developed in this study is thus divided in two steps. First is the calibration phase, in which a dense network of stations measuring surface temperature is used in 
conjunction with a scintillometer and profile measurements to identify the location of "index" stations. These stations measure a surface temperature that is representative of the source area. Indeed, once their measurements of surface temperature are used in MOS equations, they can provide an accurate estimate of the sensible heat flux. The second step is to operate only with profile measurements and with surface temperature measurements at the index stations.

The selection of an appropriate site for the index station is crucial, as it has been shown that some stations measuring the surface temperature inside the source area could lead to an erroneous estimate of the sensible heat flux.

In the absence of a network of observations, the calibration phase cannot be performed. For a similar environment, namely a moderately densely occupied urban site with approximately $25 \%$ vegetation cover, we suggest to locate the index station on an elevated vegetated surface located inside the source area.

Overall, this study showed that in situ measurements using wireless sensor networks provide a very useful tool to monitor urban micrometeorology.

Acknowledgments The authors are grateful to all the people involved in the LUCE measurement campaign: François Ingelrest, Hendrik Huwald, Julien Mezzo and the EPFL—Environmental Engineering design class. They would like to thank Claudio Carneiro for providing the campus digital elevation model. In addition, they are grateful to the three anonymous reviewers whose comments helped improve the original manuscript. This work is in part supported by the National Competence Center in Research on Mobile Information and Communication Systems (NCCR-MICS), a center supported by the Swiss National Science Foundation under grant number 5005-67322.

Open Access This article is distributed under the terms of the Creative Commons Attribution Noncommercial License which permits any noncommercial use, distribution, and reproduction in any medium, provided the original author(s) and source are credited.

\section{References}

1. Baklanov A, Mestayer PG, Clappier A, Zilitinkevich S, Joffre S, Mahura A, Nielsen NW (2008) Towards improving the simulation of meteorological fields in urban areas through updated/advanced surface fluxes description. Atmos Chem Phys 8:523-543

2. Barrenetxea G, Ingelrest F, Schaefer G, Vetterli M, Couach O, Parlange M (2008) SensorScope: outof-the-box environmental monitoring. In: International conference on information processing in sensor networks, St. Louis

3. Binkowski FS (1975) On the empirical relationship between the Richardson number and the MoninObukhov stability parameter. Atmos Environ 9:453-454

4. Bottema M (1997) Urban roughness modelling in relation to pollutant dispersion. Atmos Environ 31:3059-3075

5. Bou-Zeid E, Meneveau C, Parlange MB (2004) Large-eddy simulation of neutral atmospheric boundary layer flow over heterogeneous surfaces: blending height and effective surface roughness. Water Resour Res 40:18

6. Bou-Zeid E, Parlange MB, Meneveau C (2007) On the parameterization of surface roughness at regional scales. J Atmos Sci 64:216-227

7. Bou-Zeid E, Overney J, Rogers BD, Parlange MB (2009) The effects of building representation and clustering in large-eddy simulations of flows in urban canopies. Boundary-Layer Meteorol 132:415-436

8. Brutsaert W (1982) Evaporation into the atmosphere. D. Reidel Publ. Co., Boston

9. Brutsaert W (1998) Land-surface water vapor and sensible heat flux: spatial variability, homogeneity, and measurement scales. Water Resour Res 34:2433-2442

10. Brutsaert W (2005) Hydrology: an introduction. Cambridge University Press, Cambridge

11. Brutsaert W, Parlange MB (1992) The unstable surface layer above forest: regional evaporation and heat flux. Water Resour Res 28:3129-3134

12. Cahill AT, Parlange MB (1997) On the Brutsaert temperature roughness length model for sensible heat flux estimation. Water Resour Res 33:2315-2324 
13. Chandrasekar A, Philbrick CR, Clark R, Doddridge B, Georgopoulos P (2003) A large-eddy simulation study of the convective boundary layer over Philadelphia during the 1999 summer NE-OPS campaign. Environ Fluid Mech 3:305-329

14. De Ridder K (2006) Testing Brutsaert's temperature roughness parameterization for representing urban surfaces in atmospheric models. Geophys Res Lett 33:L13403

15. Dupont S, Otte TL, Ching JKS (2004) Simulation of meteorological fields within and above urban and rural canopies with a mesoscale model. Boundary-Layer Meteorol 113:111-158

16. Gopalakrishnan SG, Avissar R (2000) An LES study of the impacts of land surface heterogeneity on dispersion in the convective boundary layer. J Atmos Sci 57:352-371

17. Grimmond CSB (1992) The suburban energy balance: methodological considerations and results for a mid-latitude west coast city under winter and spring conditions. Int J Climatol 12:481-497

18. Grimmond CSB, Oke TR (1999) Aerodynamic properties of urban areas derived from analysis of surface form. J Appl Meteorol 38:1262-1292

19. Grimmond CSB, King TS, Roth M, Oke TR (1998) Aerodynamic roughness of urban areas derived from wind observations. Boundary-Layer Meteorol 89:1-24

20. Gurtz J, Zappa M, Jasper K, Lang H, Verbunt M, Badoux A, Vitvar T (2003) A comparative study in modelling runoff and its components in two mountainous catchments. Hydrol Process 17:297-311

21. Hadfield MG, Cotton WR, Pielke RA (1992) Large-eddy simulations of thermally forced circulations in the convective boundary layer. Part II: the effect of changes in wavelength and wind speed. BoundaryLayer Meteorol 58:307-327

22. Hignett P (1994) Roughness lengths for temperature and momentum over heterogeneous terrain. Boundary-Layer Meteorol 68:225-236

23. Horst TW (1999) The footprint for estimation of atmosphere-surface exchange fluxes by profile techniques. Bound-Layer Meteorol 90:171-188

24. Hutcheron R, Johnson R, Lowry W, Black C, Hadley D (1967) Observations of urban heat island in a small city. B Am Meteorol Soc 48:7-9

25. Ingelrest F, Barrenetxea G, Schaefer G, Vetterli M, Couach O, Parlange MB (2010) SensorScope: application specific sensor network for environmental monitoring. ACM Trans Sensor Netw 6(2)

26. Justice CO, Vermote E, Townshend JRG, Defries R, Roy DP, Hall DK, Salomonson VV, Privette JL, Riggs G, Strahler A, Lucht W, Myneni RB, Knyazikhin Y, Running SW, Nemani RR, Zhengming W, Huete AR, Leeuwen Wvan, Wolfe RE, Giglio L, Muller J, Lewis P, Barnsley MJ (1998) The Moderate Resolution Imaging Spectroradiometer (MODIS): land remote sensing for global change research. IEEE T Geosci Remote 36:1228-1249

27. Kanda M, Moriwaki R, Roth M, Oke T (2002) Area-averaged sensible heat flux and a new method to determine zero-plane displacement length over an urban surface using scintillometry. Boundary-Layer Meteorol 105:177-193

28. Kanda M, Kanega M, Kawai T, Moriwaki R, Sugawara H (2007) Roughness lengths for momentum and heat derived from outdoor urban scale models. J Appl Meteorol Climatol 46:1067-1079

29. Kastner-Klein P, Rotach MW (2004) Mean flow and turbulence characteristics in an urban roughness sublayer. Boundary-Layer Meteorol 111:55-84

30. Kohsiek W, De Bruin HAR, The H, Hurk B (1993) Estimation of the sensible heat flux of a semi-arid area using surface radiative temperature measurements. Boundary-Layer Meteorol 63:213-230

31. Malhi Y (1996) The behaviour of the roughness length for temperature over heterogeneous surfaces. Q J R Meteorol Soc 122:1095-1125

32. Masson V (2000) A physically-based scheme for the urban energy budget in atmospheric models. Boundary-Layer Meteorol 94:357-397

33. Matheron G (1969) Le krigeage universel. In: Les cahiers du centre de morphologie mathématique de Fontainebleau, vol I. École des Mines de Paris, Paris

34. Monin AS, Yaglom AM (1971) Statistical fluid mechanics, vol I. MIT, Cambridge

35. Oke TR (1973) City size and the urban heat island. Atmos Environ 7:769-779

36. Owen PR, Thomson WR (1963) Heat transfer across rough surfaces. J Fluid Mech 15:321-334

37. Parlange MB, Brutsaert W (1989) Regional roughness of the Landes forest and surface shear stress under neutral conditions. Boundary-Layer Meteorol 48:69-81

38. Parlange MB, Brutsaert W (1993) Regional shear stress of broken forest from radiosonde wind profiles in the unstable surface layer. Boundary-Layer Meteorol 64:355-368

39. Rooney GG (2001) Comparison of upwind land use and roughness length measured in the urban boundary layer. Boundary-Layer Meteorol 100:469-485

40. Roth M (2000) Review of atmospheric turbulence over cities. Q J R Meteorol Soc 126:941-990 
41. Roth M, Salmond J, Satyanarayana A (2006) Methodological considerations regarding the measurement of turbulent fluxes in the urban roughness sublayer: the role of scintillometery. Boundary-Layer Meteorol 121:351-375

42. Schmid HP (1994) Source areas for scalars and scalar fluxes. Boundary-Layer Meteorol 67:293-318

43. Schuepp PH, Leclerc MY, MacPherson JI, Desjardins RL (1990) Footprint prediction of scalar fluxes from analytical solutions of the diffusion equation. Boundary-Layer Meteorol 50:355-373

44. Spronken-Smith RA (2002) Comparison of summer- and winter-time suburban energy fluxes in Christchurch, New Zealand. Int J Climatol 22:979-992

45. Stewart JB, Kustas WP, Humes KS, Nichols WD, Moran MS, Bruin HARde (1994) Sensible heat fluxradiometric surface temperature relationship for eight semiarid areas. J Appl Meteorol 33:1110-1117

46. Stull RB (1988) An introduction to boundary layer meteorology. Kluwer, Dordrecht

47. Sugita M, Brutsaert W (1996) Optimal measurement strategy for surface temperature to determine sensible heat flux from anisothermal vegetation. Water Resour Res 32:2129-2134

48. Tseng YH, Meneveau C, Parlange MB (2006) Modeling flow around bluff bodies and predicting urban dispersion using large eddy simulation. Environ Sci Technol 40:2653-2662

49. Van Weverberg K, De Ridder K, Van Rompaey A (2008) Modeling the contribution of the Brussels heat island to a long temperature time series. J Appl Meteorol Climatol 47:976-990

50. Voogt JA, Grimmond CSB (2000) Modeling surface sensible heat flux using surface radiative temperatures in a simple urban area. J Appl Meteorol 39:1679-1699

51. Voogt JA, Oke TR (1997) Complete urban surface temperatures. J Appl Meteorol 36:1117-1132

52. Wanner H, Furger M (1990) The bise-climatology of a regional wind north of the Alps. Meteorol Atmos Phys 43:105-115

53. Xu W, Wooster MJ, Grimmond CSB (2008) Modelling of urban sensible heat flux at multiple spatial scales: a demonstration using airborne hyperspectral imagery of Shanghai and a temperature-emissivity separation approach. Remote Sens Environ 112:3493-3510

54. Zilitinkevich SS, Esau IN (2002) On integral measures of the neutral barotropic planetary boundary layer. Boundary-Layer Meteorol 104:371-379 